\title{
Qualidade de vida e sua relação com a espiritualidade: um estudo com idosos em instituições de longa permanência
}

\author{
Cléria Maria Lobo Bittar*, Ana Flávia Mendonça Moscardini*, Isadora Botossi Matos Vanzela ${ }^{* * *}$ \\ Vitor Arthur De Paula Souza***, Jennifer Fernanda Gomes Da Rocha****
}

\section{Resumo}

O rápido processo de envelhecimento populacional aponta para a necessidade de repensar a atenção no cuidado dos idosos, considerando a mudança de paradigmas que busca compreender a importância das crenças pessoais e espirituais e sua relação com o aumento de bem-estar e qualidade de vida dos idosos. Este estudo tem o objetivo de conhecer a percepção da qualidade de vida de idosos residentes em instituições de longa permanência para idosos e sua relação com a espiritualidade. Trata-se de um estudo descritivo de natureza qualitativa de que participaram 35 idosos de ambos os sexos, com idades entre 60 e 93 anos, de três municípios paulistas - Ribeirão Preto, Franca e São Joaquim da Barra. Esses idosos responderam a uma entrevista aberta, que foi, posteriormente, transcrita e categorizada. O estudo foi conduzido em novembro de 2015. Foram propostas duas categorias temáticas, de acordo com a técnica da análise do conteúdo: a) Qualidade de vida: saúde, lazer e autonomia; e b) Espiritualidade: bem-estar e valor para a vida. Os relatos demonstraram que os ido- sos entendiam que a qualidade de vida estava intimamente relacionada a ter saúde, lazer, autonomia para as atividades diárias e contato com familiares e amigos. Os idosos reconheceram que a religião e algumas práticas espirituais afetavam positivamente a qualidade de vida. A espiritualidade foi importante também como um sistema de valores para a vida, dimensionando atos e dirigindo ações e condutas pessoais, fatores que, segundo eles, interferiam na percepção da boa qualidade de vida. Conclui-se que a espiritualidade pode ser importante aliada para o desenvolvimento de ações nos âmbitos social, da saúde, da assistência, atuando ainda como apoio para o enfrentamento das adversidades típicas do envelhecimento e da proximidade da finitude da vida, refletindo na qualidade de vida e no bem-estar nessa fase da existência.

Palavras-chave: Espiritualidade. Idosos. Instituições de longa permanência. Qualidade de vida.

* Psicóloga. Docente do programa de mestrado e doutorado em Promoção da Saúde e do Curso de Psicologia da Universidade de Franca (Unifran), Cruzeiro do Sul, Franca, SP. Endereço para correspondência: Av. Dr. Armando Salles Oliveira, 201, Pq. Universitário, Franca, SP. E-mail: profa.cleriabittar@gmail.com

** Acadêmica do Curso de Psicologia da Unifran, Cruzeiro do Sul. E-mail: afmoscardini@gmail.com

**** Acadêmica do Curso de Psicologia da Unifran, Cruzeiro do Sul. E-mail: isadoravanzela@yahoo.com.br

***** Acadêmico do Curso de Psicologia da Unifran, Cruzeiro do Sul. E-mail: vitorarthurdps@hotmail.com

****** Psicóloga, formada na Unifran, Cruzeiro do Sul. E-mail: jennypsi@outlook.com

$\rightarrow$ http://dx.doi.org/10.5335/rbceh.v14i2.7020

Recebido em: 08.05.2017. Aceito em: 25.10.2017. 


\section{Introdução}

Segundo o Instituto Brasileiro de Geografia e Estatística (IBGE) (2011), o censo demográfico aponta que a população brasileira com 65 anos de idade ou mais, que era de 4,8\% em 1991, passou para $5,9 \%$ em 2000 e chegou a $7,4 \%$ em 2010. Já, no decênio 2005-2015, passou de $9,8 \%$ para $14,3 \%$ (IBGE, 2016). A velhice, fase que indica o ápice do processo de envelhecimento, é uma fase da vida influenciada por fatores biológicos, socioculturais e históricos. Além disso, tem características heterogêneas e individuais, cuja vivência varia de pessoa para pessoa, de acordo com o momento da vida e seus acontecimentos (MERCADANTE, 2005; ÁVILA; GUERRA; MENESES, 2007; SCHNEIDER; IRIGARAY, 2008).

O crescimento expressivo da população idosa no Brasil merece cada vez mais a atenção da sociedade em geral, para que a garantia de direitos básicos - como saúde, educação, acessibilidade urbana, atenção social, entre outros - reflita adequadamente na qualidade de vida desse segmento da população.

Por qualidade de vida (QV) entende-se:

[...] a percepção do indivíduo de sua posição na vida, no contexto de sua cultura e no sistema de valores em que vive e em relação a suas expectativas, seus padrões e suas preocupações (FLECK et al., 2008, p. 25, grifo do autor).

É um conceito que tem múltiplas dimensões e diz respeito à adaptação de indivíduos e grupos humanos às vicissitudes de diferentes épocas, sociedades e fases no ciclo da vida, e, para sua avaliação, tomam-se como referência diversos critérios, tais como os valores culturais, éticos, religiosos e pessoais que influenciam a forma como a $\mathrm{QV}$ é percebida pelas pessoas (NERI, 2008).

Em relação à $Q V$ na velhice, sabe-se da sua difícil operacionalização. Isso se dá em decorrência de vários motivos. Primeiro, o constructo apresenta múltiplas dimensões; segundo, resulta da atuação de muitos eventos concorrentes, ou seja, é multideterminado; terceiro, refere-se à adaptação de indivíduos e grupos de pessoas em diferentes épocas da vida de uma ou várias sociedades. Por fim, tanto a velhice como a $\mathrm{QV}$ são eventos dependentes do tempo (NERI, 2008). Paschoal (2006) questiona quais seriam os determinantes de $\mathrm{QV}$ na velhice, uma vez que a $Q V$ engloba uma enorme variedade de dimensões a ser aferidas. Uma dessas dimensões é a espiritualidade, que está muito relacionada com 0 processo de envelhecimento.

O estudo de Lucchetti et al. (2011) concluiu que o envelhecimento apresenta uma relação íntima com a espiritualidade nos mais diferentes aspectos, tendo impacto para o envelhecimento bem-sucedido e também nos cuidados recebidos no fim da vida. Diante desse cenário, a espiritualidade surge como um dos fatores mais preponderantes para o aumento ou a manutenção da QV, sobretudo em grupos de idosos (CENTRO DE PESQUISA DA VISÃO INTEGRATIVA, 2007; PANZINI et al., 2007; MELO et al., 2015).

A dimensão da espiritualidade é igualmente relevante quando associada à esperança, trazendo novos significados para a 
vida, sobretudo em tempos de dificuldades e adversidades (SOUZA et al., 2017).

Considerando os diferentes acontecimentos na vida de idosos e a sua individualidade, destaca-se, neste estudo, a importância de conhecer a percepção de QV daqueles que residem em instituições de longa permanência para idosos (Ilpis), que pode ser diferente da de outros idosos. Além disso, entende-se que a espiritualidade pode ser uma forma de enfrentar as dificuldades e os problemas - causados especialmente por distanciamento do meio familiar, isolamento social, entre outros fatores - vivenciados diariamente no processo de envelhecimento de idosos institucionalizados.

Apoiados no conceito, proposto pela Organização Mundial de Saúde (OMS), de que saúde não é ausência de doença, mas um estado de bem-estar físico, mental e social, estudos sobre características subjetivas, como esperança, resiliência e espiritualidade, receberam espaço na literatura acadêmica sobre $\mathrm{QV}$, porque se entende que esses valores podem ser importantes mediadores no âmbito da saúde e da vida (PANZINI et al., 2007; REIS; MENEZES, 2017). Trata-se de um novo paradigma nas ciências que reconhece a possibilidade de encontrar, nos recursos naturais, culturais, sociais e de crenças pessoais, os meios para produzir saúde e bem-estar (BUSS, 2000).

É especificamente na Carta de Sundsvall que a espiritualidade aparece como um dos recursos para melhorar a QV das pessoas (BRASIL, 2002). Esse documento é fruto da Terceira Conferência Internacional sobre Promoção da Saúde: ambientes favoráveis à saúde, realizada em 1991 em Sundsvall, Suécia. O evento contou com a participação de 81 países, que se comprometeram em criar e incentivar programas e políticas que visassem à promoção de ambientes mais favoráveis e saudáveis, uma meta que ficou conhecida como "Saúde para todos no ano 2000".

Diante dessas questões, viver mais e melhor constitui um desafio para toda a sociedade. Assim, torna-se importante o conhecimento dos atributos que estão relacionados à $\mathrm{QV}$ na velhice, termo que pode ter um significado diferente para cada pessoa (LIMA; VILLELA; BITTAR, 2014).

Diante do exposto, o presente estudo tem como objetivo conhecer a percepção sobre a QV de idosos residentes em Ilpis, buscando entender se a espiritualidade tem alguma influência nesse ponto. Posteriormente, busca-se conhecer a existência de outros determinantes relevantes para a $Q V$, o bem-estar e a saúde em geral desses idosos.

\section{Método}

Trata-se de um estudo de natureza qualitativo-descritiva de que participaram 35 idosos de ambos os sexos, sendo 15 mulheres e 20 homens com idades entre 60 e 93 anos, residentes há pelo menos um ano em Ilpis de três diferentes municípios paulistas (Ribeirão Preto, Franca e São Joaquim da Barra). Todos os idosos aceitaram participar espontaneamente deste estudo.

A amostra foi definida com base na disponibilidade de idosos internos em cada uma das Ilpis no momento da coleta 
de dados, bem como em uma pré-seleção dos indivíduos com menor comprometimento cognitivo, segundo resultados do Mini-Exame do Estado Mental (Meem), realizado pelas psicólogas das Ilpis. O Meem é um exame de rastreio cognitivo para idosos, criado nos Estados Unidos da América em 1975, traduzido e validado no Brasil por Bertolucci et al. (1994).

O estudo foi aprovado pelo Comitê de Ética em Pesquisa da Universidade de Franca, sob o Protocolo no 49956315.8.0000.5495, conforme Resolução no 466/2012, do Conselho Nacional de Saúde. As entrevistas foram realizadas em novembro de 2015, respeitando a integralidade e o sigilo de cada participante, e os entrevistados assinaram o termo de consentimento livre e esclarecido. As entrevistas foram gravadas e posteriormente transcritas.

Para a coleta dos dados, foram feitas quatro perguntas abertas, cuja intenção era conhecer a percepção dos idosos a respeito da $Q V$, seu estado de saúde e o seu entendimento sobre espiritualidade, a saber: 1) o que o(a) senhor(a) entende por QV?; 2) o(a) senhor(a) tem planos para o futuro?; 3) o que o(a) senhor(a) entende por espiritualidade?; e, finalmente, 4) em sua opinião, há uma relação entre espiritualidade e QV?

Após a transcrição, adotou-se a categorização temática com base na análise do conteúdo, conforme estipula Bardin (2011). Esse procedimento envolve pré-análise e organização do material após leitura exaustiva (leitura flutuante), com organização dos dados e análise e compreensão dos discursos dos participantes.

\section{Resultados e discussão}

A Tabela 1 apresenta, em números, a caracterização dos participantes da pesquisa, com as variáveis sexo, idade, número de filhos, estado civil e religião.

Tabela 1 - Descrição do perfil sociodemográfico

\begin{tabular}{|c|c|}
\hline Variáveis & $\mathrm{N}$ \\
\hline \multicolumn{2}{|l|}{ Sexo } \\
\hline Feminino & 14 \\
\hline Masculino & 21 \\
\hline \multicolumn{2}{|l|}{ Estado civil } \\
\hline Solteiro/a & 12 \\
\hline Casado/a & 04 \\
\hline Viúvo/a & 08 \\
\hline Amigado/a 1 & 02 \\
\hline Separado/a, desquitado/a & 09 \\
\hline \multicolumn{2}{|l|}{ Filhos } \\
\hline Sim & 22 \\
\hline Não & 13 \\
\hline \multicolumn{2}{|l|}{ Idade } \\
\hline $60-65$ & 04 \\
\hline $66-70$ & 04 \\
\hline $71-75$ & 09 \\
\hline $76-80$ & 09 \\
\hline $81-85$ & 05 \\
\hline$\geq 85$ anos & 04 \\
\hline \multicolumn{2}{|l|}{ Escolaridade } \\
\hline Analfabeto/a & 04 \\
\hline Fundamental incompleto & 16 \\
\hline Fundamental completo & 02 \\
\hline Médio incompleto & 05 \\
\hline Médio completo & 05 \\
\hline Superior incompleto & - \\
\hline Superior completo & 03 \\
\hline \multicolumn{2}{|l|}{ Religião } \\
\hline Católico/a & 27 \\
\hline Testemunha de Jeová & 01 \\
\hline Evangélico/a & 02 \\
\hline Espírita & 02 \\
\hline Cristão/ãa & 03 \\
\hline \multicolumn{2}{|l|}{ Tempo na Ilpi } \\
\hline$\leq 4$ anos & 24 \\
\hline 5-10 anos & 09 \\
\hline
\end{tabular}

Fonte: primária.

Notas: ${ }^{1}$ Termo que designa uma relação de união estável, conforme os dizeres dos participantes. ${ }^{2}$ Termo que designa o rompimento de uma união estável ou casamento, conforme os dizeres dos participantes. ${ }^{3}$ Alguns participantes não se denominaram em termos de ser seguidores de uma crença ou religião específica, preferindo genericamente autodenominar-se cristãos. 
Dos 35 participantes, 14 eram do sexo feminino e 21 do sexo masculino. O tempo de permanência na instituição variou entre 1 e 13 anos, mas a maioria $(\mathrm{N}=24)$ estava há menos de 4 anos institucionalizada, e a faixa etária mais predominante foi entre 71 e 80 anos. Dos participantes do estudo, 16 não concluíram o ensino fundamental; 5 não concluíram o ensino médio; 4 nunca frequentaram a escola; 3 concluíram o ensino superior. A maioria era solteira, sendo que viúvos e separados praticamente estavam na mesma proporção.

Estudos apontam que a baixa escolaridade bem como a condição de viver sozinho devido ao estado civil são fatores que aumentam a probabilidade de institucionalização (ALENCAR et al., 2012; REIS; JESUS, 2015; CORDEIRO et al., 2015). Estudo realizado por Modeneze et al. (2013) apontou que a escolaridade resultou em melhores escores nos domínios físico e ambiental nos resultados dos questionários WHOQOL-old e WHOQOL-bref, que avaliam a QV. Defendem os autores que a maior escolaridade aumenta a participação em atividades sociais e de grupo e melhora o autocuidado, refletindo na saúde como um todo e na percepção da QV.

A literatura tem demonstrado o predomínio de idosas na população em geral (PAVAN; MENEGHEL; JUNGES, 2008; PARAHYBA; VERAS; MELZER, 2005; LIMA; BUENO, 2009; ALMEIDA, 2015; ALVES, 2016). Decorrente desse processo de "feminização" da velhice, há naturalmente um predomínio de idosas institucionalizadas. Entretanto, este estudo evidenciou um predomínio de idosos, o que também foi verificado em estudo realizado por Lima (2014) em cinco municípios da região do Triângulo Mineiro, e, em estudos realizados em diferentes Ilpis no país, também foi encontrado predomínio de homens (GAIÃO; ALMEIDA; HEUKELBACH, 2005; CASTELLAR et al., 2007; FREITAS et al., 2011; ALVES; SCHEICHER, 2011). Conforme comentam Alencar et al. (2012), esses resultados podem indicar uma mudança do perfil de idosos institucionalizados em algumas cidades ou mesmo novos arranjos familiares em desenvolvimento.

A religião com maior número de adeptos é a católica ( $\mathrm{N}=27)$, e as demais, em menor representatividade entre os participantes, são todas de matriz cristã. Se os ofícios religiosos e a espiritualidade são de fundamental importância para os seres humanos, ganham forma maior com a chegada da velhice, quando o indivíduo é acometido por incertezas, doenças e, muitas vezes, submetido ao afastamento familiar ou a perdas por morte. Sendo assim, este processo de espiritualidade e fé não deve ser deixado em segundo plano, uma vez que dessas práticas é que o idoso retira força para superar seus conflitos, como isolamento, solidão, abandono, sensação de perda familiar e de afetividade (OLIVEIRA; ALVES, 2014).

Após a transcrição das entrevistas, a leitura dos relatos dos participantes e a identificação dos eixos temáticos, conforme a técnica da análise do conteúdo (BARDIN, 2011), iniciou-se a construção 
das categorias de análise. Foram identificadas duas categorias principais: 1) Qualidade de vida: saúde, lazer e autonomia; e 2) Espiritualidade: bem-estar e valores para a vida. Os participantes da pesquisas, num total de 35 , estão identificados pela letra $\mathrm{P}$ (Participante) e o número.

\section{1) Qualidade de vida: saúde, lazer e autonomia}

As temáticas relacionadas a saúde, lazer, trabalho, autonomia e relacionamentos sociais foram associadas diretamente com a $\mathrm{QV}$, percebida ainda como sinônimo de convivência com a família e com amigos e ausência de maiores preocupações.

Qualidade de vida é quando você tá com a saúde boa, tem condições de sair, viajar, ir aonde você gosta de ir, ter hora de lazer, conversar, ir ao cinema, festival, teatro (P7).

É viver bem, comer bem, dormir bem, fazer o que quer, não se preocupar com nada, eu não me preocupo com nada (P27).

Qualidade de vida é uma vida com a família, filhos, comunhão, cê entendeu? É você ter uma coisa com que você se alimentar, desfrutar (P18).

É participar da folia de reis nas cidades vizinhas (P35).

Alguns participantes tinham planos para o futuro, sonhos associados ao trabalho e a realizações pessoais, como viajar, voltar a viver com a família ou mesmo trabalhar.
Eu tenho, assim, que minha vida melhore, e que meus filhos fiquem bem. Eu gosto muito dos meus filhos e netos, quero que eles fiquem bem para que eles cuidem de seus filhos (P35).

Sim. Sair daqui e ficar com minha família e viajar, pelo menos mais uma viagem (P8).

Quero rever meus filhos e minha familia, estou fora do Rio de Janeiro há 20 anos (P30).

Tenho planos, sim. Se eu ficar bom mesmo, quero trabalhar. Trabalho é diversão para $\operatorname{mim}(\mathrm{P} 6)$.

Como é possível observar, os fatores relacionados às dimensões fisiológicas, psicológicas, sociais e ambientais são os mais relacionados à $\mathrm{QV}$ na percepção dos idosos, basicamente, fatores que apontam para a manutenção da autonomia, entendida como a possibilidade de escolher com quem estar, o que fazer e onde permanecer.

Uma pesquisa realizada com idosos institucionalizados no Rio Grande do Norte concluiu que é preciso ampliar os programas de promoção de saúde voltados para a QV em idosos residentes em Ilpis, principalmente no que se refere à autonomia, visando à melhor $\mathrm{QV}$ e, consequentemente, à melhor saúde e ao bem-estar social (NUNES; MENEZES; ALCHIERI, 2010).

Deve-se atentar para as atividades de lazer que consideram as necessidades subjetivas dos idosos, não apenas as atividades que se guiem por propostas com aspectos funcionais (GIRALDI, 2014), uma vez que muitos dos programas e ações destinados a esta faixa etária negam-lhe sua condição de idosos, tomando 
como modelo desejável o estilo de vida da juventude, em um processo que Couto e Meyer (2011) chamam de "juvenilização da velhice".

Sobre o apoio social recebido de familiares e amigos, sabe-se da sua significativa importância para os idosos, influenciando, inclusive, para a longevidade (ARGIMON; VITOLA, 2009; AEROSA et al., 2012). Para Cornelia et al. (2013), a rede social familiar tem um papel positivo, promovendo resiliência, apoio, saúde mental e física, além de ser a mais estável ao longo da existência.

O trabalho também aparece como algo desejável, ainda que todos os idosos fossem aposentados e/ou pensionistas. O trabalho como valor é algo muito cultuado na sociedade ocidental. Estudos mostram que algumas pessoas têm dificuldades em aceitar a condição de aposentadas, como se houvesse um perda de identidade, uma vez que é pelo mundo do trabalho que a pessoa é reconhecida, fomenta e constitui suas relações sociais, construindo, portanto, sua identidade em torno do trabalho (CARDOSO, 2016; ZANELLI; SILVA; SOARES, 2010). Os anos que se seguem à aposentadoria representam, para muitos, a perda dessa identidade, dos contatos sociais. Estando fora do mercado de trabalho, há uma precariedade e uma fragilidade estabelecidas na relação produção-consumo, o que, segundo França (2002), pode levar os aposentados a um comportamento de isolamento social e até mesmo a quadros depressivos, por fomentar o estereótipo da velhice improdutiva. Por isso, para alguns participantes, o trabalho é fator relevante para a manutenção da $\mathrm{QV}$, conservando, portanto, a esperança de que possam voltar a exercê-lo.

Segundo Lawton, "qualidade de vida na velhice é uma avaliação multidimensional referenciada a critérios socionormativos e intrapessoais, a respeito das relações atuais, passadas e prospectivas entre o indivíduo maduro ou idoso e o seu ambiente" (1991, p. 6, tradução nossa). Assim, a QV na velhice é dependente de muitos elementos em interação constante ao longo da vida do indivíduo. Para o autor, a avaliação de $\mathrm{QV}$ incide sobre quatro áreas sobrepostas e inter-relacionadas: competência comportamental, condições ambientais, qualidade de vida percebida e bem-estar psicológico, das quais depende a funcionalidade do idoso.

Não é à toa que os temas apontados pelos participantes do estudo quanto à QV sejam exatamente os fatores apresentados na literatura, sobretudo no que tange a manutenção da saúde, autonomia para as atividades da vida diária e independência para as escolhas pessoais.

\section{2) Espiritualidade: bem-estar e valores para a vida}

Os idosos atribuíram à espiritualidade um significado operacional, creditando-lhe um modo eficiente de enfrentamento de dificuldades, e também transcendental, quando assumem que a fé e a crença na existência de Deus atribuíam-lhes sentido à vida, sendo a religião importante sistema de valor que regula os atos morais dos homens. 
Eu acho que é um modo de vida: fazer o bem sem olhar a quem (P10).

É o modo de você ver, sentir e encarar os problemas, porque muitas vezes uma palavra não fere a mim, mas te fere, e, na religiosidade, é coisa que você tem que respeitar $o$ do outro (P23).

Não vou falar da religião, vou falar de Deus. A última coisa que o homem perde na vida é a fé em Deus. Se ele perde essa fé, acabou (P35).

A espiritualidade te deixa muito bem, uma coisa muito boa, ensinam muitas coisas (P5).

A espiritualidade pode dar alguns valores para a pessoa (P8).

Mesmo aqueles que declararam não ser praticantes assíduos de uma religião, reconheceram que se sentiam bem em se envolver em grupos de oração como forma de participação ativa na vida social. Os grupos de oração e as atividades religiosas em grupo promovem as condições ideais para a criação de redes de apoio mútuo entre os idosos - institucionalizados ou não -, despertando o sentimento de pertencimento, com reflexo positivo no bem-estar e na QV (LIMA; VILLELA; BITTAR, 2014).

O bem-estar envolve uma gama de fatores, sendo um conceito ainda vago nos estudos de gerontologia, apesar de bastante utilizado. Doll (2006) comenta a importância de se dar voz às pessoas idosas, para conhecer o que lhes dá sentido às suas vidas; e a espiritualidade é um fator a ser considerado.
A experiência espiritual parece ser capaz de suscitar emoções positivas autorrealizadoras, propiciando a sinergia social e a sensação de pertença grupal, sentimentos de comunhão com o universo e com a humanidade, fortalecendo os laços intra e interpessoais, dando as ferramentas para que as pessoas possam enfrentar suas rotinas com serenidade (FADIMAN; FRAGER, 1986; MASLOW, 1989; PERES; SIMAO; NASELLO, 2008).

Diante do fim do ciclo vital, existe a possibilidade de alguns idosos procurarem mudanças de hábitos, redenção e acolhimento, fatos que culminam no acolhimento de demandas emocionais e angústias que outrora se manifestavam de forma cristalizada e fonte de sofrimento. Por esse motivo, as redes de apoio existentes nas Ilpis devem considerar a realidade da vivência espiritual/religiosidade para expandir sentidos, explorar possibilidades ou até mesmo a esperança de transcendência e resiliência, fenômenos nos quais a espiritualidade assume importante função.

Para Vasconcelos (2006), a transcendência assume papel norteador da consciência humana e, aliada à espiritualidade, permite abertura para experiências de autocura, aceitação, serenidade, paz e bem-estar.

A resiliência - capacidade individual ou grupal de enfrentamento das adversidades - é ainda entendida como "uma tendência, que se manifesta por ocasião da superação de situações de risco e assegura a continuidade de um desenvolvimento saudável" (SOUSA; ARAUJO, 2015, p. 902), abrangendo características 
diversas de cunho pessoal, cognitivo, social e cultural para se desenvolver. Por esse viés, Chequini comenta sobre a importância da fé/espiritualidade para o fortalecimento da resiliência, pois a espiritualidade "é a pedra angular da resiliência, capaz de promovê-la e mediá-la" (2007, p. 95, grifo do autor).

A espiritualidade é inerente à natureza humana em sua dimensão psíquica. Para muitas pessoas, é um importante fator que contribui para uma atitude positiva e ativa, atuando na melhora da QV, no bem-estar e na saúde em geral. Segundo Gussi e Dytz (2008), pela teoria do cuidado transpessoal, parte-se da premissa de que a força espiritual - condição psíquica interna de uma pessoa - é capaz de transformá-la e de curá-la, estabelecendo equilíbrio e bem-estar.

Considerando a situação dos idosos institucionalizados, para que esse potencial espiritual se manifeste no sentido da transformação desejável, é necessário que seja legitimado e que os cuidadores também o reconheçam em si mesmos e no outro, em uma postura filosófica, que implica uma abertura mental na crença da força interna de todo ser humano e a instilação de fé-esperança (GUSSI; DYTZ, 2008).

É importante o reconhecimento por parte dos profissionais e demais cuidadores sobre o papel que a espiritualidade exerce na melhora da $\mathrm{QV}$ do idoso, bem como sobre a influência de outros fatores, como saúde e autonomia, pois caracteriza um cuidado humanizado. $\mathrm{O}$

[...] cuidado humanizado requer reverência pela vida [...], que pode ser demonstrado pela valorização da autonomia e pela livre possibilidade de escolhas, fortalecendo, assim, o autoconhecimento, o autocontrole, a disposição para autocura (SCHOSSLER; CROSSETTI, 2008, p. 281).

O estudo de Oliveira e Alves (2014) enfatiza a importância da assistência prestada à pessoa idosa institucionalizada no que diz respeito à religiosidade/ espiritualidade. Eles identificaram que os idosos institucionalizados são carentes de afeto por parte de suas famílias e que se apegam fortemente às questões religiosas e espirituais para enfrentar os vários desafios diários, em especial, os naturais da vida senil.

A vivência espiritual, diretamente relacionada ou não com uma religião, é um processo cuja natureza transcende os limites da atividade puramente humana e que confere algum sentido para a existência do idoso. Está associada com o aumento de resiliência e resistência ao estresse e às doenças (PANZINI; BANDEIRA, 2007).

Ressalta-se que, neste estudo, muitos idosos entenderam inicialmente $o$ termo espiritualidade como sinônimo de espiritismo, o que pode ter afetado a resposta sobre a associação entre $\mathrm{QV}$ e espiritualidade, representando uma possível limitação. Notou-se também a importância da figura de Deus em suas vidas. Em estudo realizado com idosos institucionalizados no estado de São Paulo, Deus foi mencionado como "a pessoa mais importante" para superar as adversidades, sendo reconhecidos o valor e a importância da religiosidade, da fé e da espiritualidade (CARMO et al., 2012). 
O estudo conduzido por Santos et al. (2013) demonstrou a importância da figura de Deus para o enfrentamento da incapacidade funcional em idosos, além do conforto diante das perdas funcionais típicas da velhice, trazendo-lhes maior resignação e aceitação. Também Sommerhalder e Goldstein (2006) tratam as temáticas da religiosidade e da espiritualidade na vida adulta, apontando-as como importante recurso de enfrentamento dos aspectos relativos às perdas funcionais, ao luto do cônjuge, entre outros sentimentos e perdas típicos dessa fase.

Há consenso de que, para avaliar a QV na velhice, é necessária a utilização de uma abordagem multidimensional, e, apesar de não existir acordo sobre as dimensões que constituem esse constructo, a dimensão da espiritualidade/ religiosidade tem ganhado destaque e importância, juntamente com o reconhecimento das outras dimensões (física, psicológica, social, ambiental).

Quando reconhecida pelos profissionais e também pelas redes de apoio social que circundam a vida do sujeito, a religiosidade/espiritualidade tem se mostrado eficiente na manutenção de bons níveis de $\mathrm{QV}$, resiliência e bem-estar, preparando os idosos para o confronto e o enfrentamento de situações adversas e comuns na vida, assim como para a aceitação do próprio processo de encerramento do ciclo vital (CENTRO DE PESQUISA DA VISÃO INTEGRATIVA, 2007).

Diante do exposto, estudos têm demonstrado evidências do papel da espi- ritualidade e do seu impacto na saúde, orientando os profissionais para que se aprofundem na temática e na abordagem, tanto para oferecer um atendimento humanizado, como para maximizar a eficácia do tratamento, tema que tem se consolidado na literatura científica, sobretudo nas últimas décadas (CORTEZ, 2012; SAAD; MASIERO; BATTISTELLA, 2016). Conforme definem Saad, Masiero e Battistella (2016), não se está falando em medicina complementar ou em algo dessa natureza, mas de evidências científicas que devem ser respeitadas e que podem nortear as ações dos profissionais da saúde em suas práticas.

\section{Considerações finais}

O estudo demonstrou que a espiritualidade, de fato, pode ser um fator relevante na $\mathrm{QV}$ de idosos residentes em Ilpis, todavia, a espiritualidade, isoladamente, não foi determinante na definição de QV para os idosos. Fatores como integridade física, autonomia, vida social ativa, boa saúde, preservação das habilidades motoras e mentais, manutenção dos laços afetivos com familiares e amigos foram igualmente considerados importantes na $\mathrm{QV}$ dos participantes do estudo.

Alguns idosos mantêm a espiritualidade e/ou os dogmas religiosos como valores de vida que lhes oferecem, além de um modelo de conduta a ser seguido, conforto e esperança ao confrontar o final do ciclo vital. Consequentemente, surgem as possibilidades de aproximação e formação de laços afetivos, facilitados 
pela consonância de convicções sobre a espiritualidade/religiosidade, proximidade propiciada nos grupos religiosos de convivência.

Finalmente, pode-se afirmar que a espiritualidade esteve implicada na percepção de QV em residentes de Ilpis de forma indireta, apesar de não ser determinante na definição de QV. Dessa forma, a espiritualidade contribuiu para o enfrentamento e a aceitação da proximidade do fim do ciclo de vida, norteando os valores para a vida e também fomentando a crença na manutenção de uma existência da própria essência na ordem do além-corpo; o que, no âmbito social, facilita e promove o relacionamento entre os idosos.

Diante do exposto, conclui-se que a temática não pode ser excluída de estudos sobre QV na velhice, muito menos esquecida durante a formulação das ações de promoção de saúde em Ilpis.

\section{Agradecimento}

Ao programa de bolsa de iniciação científica da Unifran e aos idosos residentes nas Ilpis das cidades de Franca, Ribeirão Preto e São Joaquim da Barra, no estado de São Paulo.

\section{Quality of life and its relation with spirituality: a case with elderly in long staying residences}

\section{Abstract}

The rapid process of population aging points to the need to rethink care of the elderly, paying attention to paradigm shifts in attention to the elderly that seeks to understand the importance of personal and spiritual beliefs and their relationship with the increase of well- being and quality of life. This study aims to understand the perception of the quality of life of elderly people living in long-term care facilities and its relationship with spirituality. This is a descriptive study of a qualitative nature in which thirty-five elderly people of both sexes, aged 60 to 93 years, from three São Paulo municipalities - Ribeirão Preto, Franca and São Joaquim da Barra, responded to an open interview that was later transcribed and categorized. The study was conducted in November 2015. Two thematic categories were proposed, according to the Analysis of the Content technique: a) Quality of life: health, leisure and autonomy, and b) Spirituality: well-being and value for life. The reports showed that the elderly understood that quality of life was closely related to health, leisure activities, maintenance of autonomy for daily activities and contact with relativities and friends. Recognized as well, that religion or spiritual practices, positively affected the quality of life. Spirituality was also important as a value system for life, dimensioning acts and directing personal actions and behaviors, factors that, according to them, interfered in the perception of a good quality of life. It is concluded that spirituality can be important both for the development of actions in the social, health, and care spheres, acting as support for coping 
with the typical adversities of aging and the proximity of the finitude of life, reflecting on the quality of life and well- being at this stage of existence.

Keywords: Elderly. Long-term institutions. Quality of life. Spirituality.

\section{Referências}

AEROSA, S. V. C. et al. Envelhecimento: relações pessoais e familiares. Barbarói, Santa Cruz do Sul, v. 36, ed. esp., p. 120-132, jan./jun. 2012.

ALENCAR, M. A. et al. Perfil dos idosos residentes em uma instituição de longa permanência. Revista Brasileira de Geriatria e Gerontologia, Rio de Janeiro, RJ, v. 15, n. 4, p. 785-796, 2012.

ALMEIDA, A. V. O processo de feminização da velhice no municipio de Viçosa, MG: características, relações e risco social. Dissertação (Mestrado em Economia Doméstica) - Programa de Pós-Graduação em Economia Doméstica, Universidade Federal de Viçosa, Viçosa, 2015.

ALVES, J. E. D. As mulheres e o envelhecimento populacional no Brasil. Laboratório de demografia e estudos populacionais. UFJF, janeiro de 2016. Disponível em: <http://www. ufjf.br/ladem/2016/01/29/as-mulheres-e-o-envelhecimento-populacional-no-brasil-artigo-de-jose-eustaquio-diniz-alves/>. Acesso em: 23 mar. 2016.

ALVES, N. B; SCHEICHER, M. E. Equilíbrio postural e risco para queda em idosos da cidade de Garça, SP. Revista Brasileira de Geriatria e Gerontologia, Rio de Janeiro, v. 14, n. 4 , p. 763-768, 2011.

ARGIMON, I. I. de L.; VITOLA, J. C. E a família, como vai? In: BULLA, Leonia Capaverde; ARGIMON, Irani Iracema de Lima (Org.). Convivendo com o familiar idoso. Porto Alegre: EDIPUCRS, 2009. p. 25-31.
ÁVILA, A. H.; GUERRA, M.; MENESES, P. R. Se o velho é o outro, quem sou eu? A construção da auto-imagem na velhice. Pensamento Psicológico, Colômbia, v. 3, n. 8, p. 7-18, jan./jun., 2007.

BARDIN, L. Analise de conteúdo. São Paulo: Edições 70, 2011.

BERTOLUCCI, P. H. F et al. O miniexame do estado mental em uma população geral. Impacto da escolaridade. Arquivos de Neuropsiquiatria, v. 52, n. 1, p. 1-7, 1994.

BRASIL. Ministério da Saúde. Secretaria de Políticas de Saúde. Projeto Promoção da Saúde. As Cartas da Promoção da Saúde. Brasília: Ministério da Saúde, 2002.

BUSS, P. M. Promoção da saúde e qualidade de vida. Ciência e saúde coletiva. Rio de Janeiro, v. 5, n. 1, p. 163-177, 2000.

CARDOSO, C. M. Trabalho e identidade do idoso em municípios de pequeno porte da região do Vale do Rio Pardo (RS). Dissertação (Mestrado em Desenvolvimento Regional) Programa de Pós-Graduação em Desenvolvimento Regional, Universidade de Santa Cruz do Sul, Santa Cruz do Sul, 2016.

CARMO, H. O. et al. Idoso institucionalizado: o que sente, percebe e deseja? Revista Brasileira de Ciências do Envelhecimento Humano, Passo Fundo, v. 9, n. 3, p. 330-340, set./dez. 2012.

CASTELLAR J. I. et al. Estudo da farmacoterapia prescrita a idosos em instituição de longa permanência. Acta Médica Portuguesa, Portugal, v. 20, p. 97-105, 2007.

CENTRO DE PESQUISA DA VISÃO INTEGRATIVA. Espiritualidade e religiosidade na saúde. 2007. Disponível em: <http://www. cpvi.com.br/materias/Espiritualidade_e_Religiosidade_na_sa\%C3\%BAde\#.U0RPsahdXv4>. Acesso em: 7 abr. 2016.

CHEQUINI, M. C. M. A relevância da espiritualidade no processo de resiliência. $P s i$ cologia Revista, São Paulo, SP, v. 16, n. 1/2, p. 93-117, 2007. 
CORDEIRO, L. M. et al. Qualidade de vida do idoso fragilizado e institucionalizado. Acta Paulista de Enfermagem, São Paulo, SP, v. 28, n. 4, p. 361-366, ago. 2015.

CORNELIA, B. W. et al. Social network changes and life events across the life span: a meta-analysis. Psychological Bulletin, v. 139 , p. 53-80, 2013.

CORTEZ, E. A. Influência da religiosidade e espiritualidade na saúde: reflexões para o cuidado de enfermagem. Online Brazilian Journal of Nursing, v. 11, n. 2, p. 418-419, 2012.

COUTO, E. S.; MEYER, D. E. Viver para ser velho? Cuidado de si, envelhecimento e juvenilização. Revista da Faculdade de Educação da Universidade Federal da Bahia, Salvador, n. 19, p. 21-32, jan./jun. 2011.

FREITAS, M. C. et al. Úlcera por pressão em idosos institucionalizados: análise da prevalência e fatores de risco. Revista Gaúcha de Enfermagem, Porto Alegre, RS, v. 32, n. 1, p. 143, 2011.

DOLL, J. Bem-estar na velhice: mitos, verdades e discursos, ou a gerontologia na pós-modernidade. Revista Brasileira de Ciências do Envelhecimento Humano, Passo Fundo, v. 3, n. 1, p. 9-21, jan./jun. 2006.

FADIMAN, J; FRAGER, R. Teorias da personalidade. Trad. Camila Pedral Sampaio e Sybil Safdié. São Paulo: Harbra, 1986.

FLECK, M. P. A. et al. Problemas conceituais em qualidade de vida. In: (Org.). $A$ avaliação de qualidade de vida: guia para profissionais da saúde. Porto Alegre: Artmed, 2008. p. 19-28.

FRANÇA, L. H. Repensando a aposentadoria com qualidade: um manual para facilitadores de programas de educação para aposentadoria em comunidades. Rio de Janeiro: Centro de Referência e Documentação sobre Envelhecimento; Universidade Aberta da Terceira Idade; Uerj, 2002.
GAIÃO, L. R; ALMEIDA, M. E. L; HEUKELBACH, J. Perfil epidemiológico da cárie dentária, doença periodontal, uso e necessidade de prótese em idosos residentes em uma instituição na cidade de Fortaleza, Ceará. Revista Brasileira de Epidemiologia, São Paulo, SP, v. 8, n. 3, p. 316-323, 2005.

GIRALDI, R. C. Espaços de lazer para a terceira idade: sua análise por meio de diferentes vertentes. Revista Brasileira de Ginecologia e Obstetrícia, Rio de Janeiro, v. 17, n. 3, p. 627-636, 2014.

GUSSI, M. A; DYTZ, J. L. G. Religião e espiritualidade no ensino e assistência de enfermagem. Revista Brasileira de Enfermagem, Brasília, v. 61, n. 3, p. 337-384, jun. 2008.

INSTITUTO BRASILEIRO DE GEOGRAFIA E ESTATÍSTICA. População idosa no Brasil cresce e diminui número de jovens, revela Censo. 2011. Disponível em: <http://www. brasil.gov.br/ciencia-e-tecnologia/2011/04/ populacao-idosa-no-brasil-cresce-e-diminui-numero-de-jovens-revela-censo >. Acesso em: 10 out. 2017.

. SIS 2016: 67,7\% dos idosos ocupados começaram a trabalhar com até 14 anos. 2016. Disponível em: <https://agenciadenoticias.ibge.gov.br/2013-agencia-de-noticias/ releases/9487-sis-2016-67-7-dos-idosos-ocupados-comecaram-a-trabalhar-com-ate-14-anos.html>. Acesso em: 10 out. 2017.

LAWTON, M. P. A multidimensional view of quality of life in frail elderly. In: BIRREN, J. E. et al. (Ed.). The concept and measurement of quality of life in the frail elderly. San Diego, CA: Academic Press, 1991. p. 3-27.

LIMA, L. C. V. Percepção sobre qualidade de vida entre idosos residentes em municípios de pequeno porte do interior de Minas Gerais. 2014. Tese (Doutorado em Promoção da Saúde) - Programa de Pós-Graduação em Promoção da Saúde, Universidade de Franca, Franca, 2014. 
LIMA, L. C. V.; BUENO, C. M. L. B. Envelhecimento e gênero: a vulnerabilidade de idosas no Brasil. Saúde Pesquisa, São Paulo, SP, v. 2, n. 2, p. 273-280, 2009.

LIMA, L. C. V.; VILLELA, W. V.; BITTAR, C. $M$. L. Percepção sobre qualidade de vida entre idosos residentes em municípios de pequeno porte e sua relação com a religiosidade/espiritualidade. Revista Brasileira de Ciências do Envelhecimento Humano, Passo Fundo, v. 11, n. 3, p. 231-244, 2014.

LUCCHETTI, G. et al. O idoso e sua espiritualidade: impacto sobre diferentes aspectos do envelhecimento. Revista Brasileira de Geriatria e Gerontologia, Rio de Janeiro, v. 14, n. 11, p. 159-167, 2011.

MASLOW, A. H. Introdução à psicologia do ser. Trad. Álvaro Cabral. Rio de Janeiro: Eldorado, 1989. (Coleção Anima).

MELO, C. de F. et al. Correlação entre religiosidade, espiritualidade e qualidade de vida: uma revisão de literatura. Estudos e Pesquisas em Psicologia, Rio de Janeiro, RJ, v. 15, n. 2, p. 447-464, jul. 2015.

MERCADANTE, E. F. Velhice: uma questão complexa. In: CÔRTE, B.; MERCADANTE, E. F.; ARCURI, I. G. (Org.). Velhice, envelhecimento, complex(idade). São Paulo: Vetor, 2005. p. 23-34.

MODENEZE, D. M. et al. Perfil epidemiológico e socioeconômico de idosos ativos: qualidade de vida associada com renda, escolaridade e morbidades. Estudos Interdisciplinares sobre o Envelhecimento, Porto Alegre, RS, v. 18 , n. 2 , p. 387-399, dez. 2013.

NERI, A. L. (Org.). Palavras-chave em gerontologia. 3. ed. Campinas: Alínea, 2008.

NUNES, V. M. A.; MENEZES, R. M. P.; ALCHIERI, J. C. Avaliação da Qualidade de Vida em idosos institucionalizados no município de Natal, Rio Grande do Norte. Acta Scientiarum. Health Sciences, Maringá, PR, v. 32, n. 2, p. 119-126, 2010.
OLIVEIRA, R. M.; ALVES, V. P. A qualidade de vida dos idosos a partir da influência da religiosidade e da espiritualidade: cuidados prestados aos idosos institucionalizados em Caetité (BA). Revista Kairós Gerontologia, São Paulo, SP, v. 17, n. 3, p. 305-327, 2014.

PANZINI, R. G. et al. Qualidade de vida e espiritualidade. Revista de Psiquiatria Clínica, São Paulo, SP, n. 34, supl. 1, p. 105-115, 2007.

PANZINI, R. G.; BANDEIRA, D. R. Coping (enfrentamento) religioso/espiritual. Revista de Psiquiatria Clínica, São Paulo, SP, n. 34, supl. 1, p. 126-135, 2007.

PARAHYBA, M. I.; VERAS, R.; MELZER, D. Incapacidade funcional entre as mulheres idosas no Brasil. Revista de Saúde Pública, São Paulo, SP, v. 39, n. 3. p. 383-391, 2005.

PASCHOAL, S. M. P. Qualidade de vida na velhice. In: FREITAS, E. V. et al. Tratado de geriatria e gerontologia. 2. ed. Rio de Janeiro: Guanabara Koogan, 2006. p. 147-153.

PAVAN, F. J.; MENEGHEL, S. N.; JUNGES, J. R. Mulheres idosas enfrentando a institucionalização. Cadernos de Saúde Pública, São Paulo, SP, v. 24, n. 9, p. 2187-2190, 2008.

PERES, J. F. P.; SIMAO, M. J. P.; NASELLO, A. G. Espiritualidade, religiosidade e psicoterapia. Revista de Psiquiatria Clínica, São Paulo, SP, v. 34, supl. 1, p. 136-145, 2008.

REIS, K. M. C.; JESUS, C. A. C. de. Coorte de idosos institucionalizados: fatores de risco para queda a partir do diagnóstico de enfermagem. Revista Latino-Americana de Enfermagem, São Paulo, SP, v. 23, n. 5, p. 1130-1138, nov./dez. 2015.

REIS, L. A. dos; MENEZES, T. M. de O. Religiosity and spirituality as resilience strategies among long-living older adults in their daily lives. Revista Brasileira de Enfermagem, Brasília, DF, v. 70, n. 4, p. 761766, ago. 2017. 
SAAD, M.; MASIERO, D.; BATTISTELLA, L. R. Espiritualidade baseada em evidências. Acta Fisiátrica, São Paulo, SP, v. 8, n. 3, p. 107-112, 2016.

SANTOS, W. J. et al. Enfrentamento da incapacidade funcional por idosos por meio de crenças religiosas. Ciência \& Saúde Coletiva, Rio de Janeiro, RJ, v. 18, n. 8, p. 2319-2328, ago. 2013.

SOMMERHALDER, C.; GOLDSTEIN, L. L. $O$ papel da espiritualidade e da religiosidade na vida adulta e na velhice. In: FREITAS, E. V. et al. Tratado de Geriatria e Gerontologia. 2. ed. Rio de Janeiro: Guanabara Koogan, 2006. p. 1307-1315.

SCHNEIDER, R. H.; IRIGARAY, T. Q. O envelhecimento na atualidade: aspectos cronológicos, biológicos, psicológicos e sociais. Estudos de Psicologia, Campinas, SP, v. 25, n. 4, p. 585-593, out./dez. 2008.

SCHOSSLER, T.; CROSSETTI, M. da G. Cuidador domiciliar do idoso d o cuidado de si: uma análise através da teoria do cuidado humano de Jean Watson. Texto \& Contexto Enfermagem, Florianópolis, SC, v. 17, n. 2, p. 280-287, abr./jun. 2008.

SOUZA, E. N. et al. Relação entre a esperança e a espiritualidade de idosos cuidadores. Texto \& Contexto Enfermagem, Florianópolis, SC, v. 26, n. 3, p. 67-77, ago. 2017.

SOUSA, V. F. da S.; ARAUJO, T. C. C. F. de. Estresse ocupacional e resiliência entre profissionais de saúde. Psicologia Ciência e Profissão, Brasília, DF, v. 35, p. 900-915, jul./set. 2015.

VASCONCELOS, E. M. (Org.). A espiritualidade no cuidado e na educação em saúde. In: A espiritualidade no trabalho em saúde. São Paulo: Hucitec; 2006. p. 13-157.

ZANELLI, J. C.; SILVA, N.; SOARES, D. H. P. Orientação para aposentadoria nas organizações do trabalho: construção de projetos para o pós-carreira. Porto Alegre: Artmed, 2010. 